\title{
Aufklärung 6.0 oder Wohlige Horror-Abende mit der Tagesschau
}

Wahrscheinlich müssten wir längst bei Aufklärung 5.o oder 6.o angelangt sein. Aber es liegt mir fern, Deine Forderung nach aktiver Partizipation als Sonntagsrede zu verunglimpfen. «Staatsversagen» wäre unser aller Versagen. Ich stimme Dir zu, dass es gegenwärtig und künftig eine andere Form des Engagements braucht, als bloss alle paar Jahre ein Kreuzchen zu machen. Aber mir scheint Deine Diagnose ein bisschen kurzatmig: Das verbreitete Unbehagen ist nicht erst wenige Jahre alt und hat seinen Ausgang auch nicht bei der «Flüchtlingskrise» genommen - oder wie immer das politisch korrekt heissen mag. Davor gab es die «Griechenlandkrise» - die angeblich gierigen Hellenen, die dem deutschen Michel die Butter vom Brot und die Oliven aus dem Salat klauen wollten. Und davor die «Finanzkrise» mit der sicheren Erwartung, dass die Weltwirtschaft binnen Kurzem implodieren würde. Und davor den 11. September mit der sicheren Erwartung, dass der Weltbürgerkrieg sehr bald alles in Schutt und Asche legen würde. Und ...

Nun werde $\mathrm{Du}$ mal nicht kurzatmig! Das waren alles veritable Krisen, keine Frage, Du könntest auch mit dem Kalten Krieg anfangen und über Tschernobyl und Sarajevo den ganzen Abend so weitermachen. Vielleicht waren wir einfach nur blind oder zu sehr mit uns selbst beschäftigt, aber all das hat uns in Deutschland ja immer nur vorübergehend und mittelbar berührt. Jetzt scheint jedoch etwas ganz grundsätzlich und unübersehbar aus den Fugen geraten zu sein, nämlich wir selbst. Da können wir uns nicht länger in Sicherheit wiegen.

Konnten wir das je wirklich? Meine These lautet: All diese Krisen sind nur Oberflächenphänomene, konjunkturelle Hysterisierungen eines Publikums, das wenigstens unterhalten sein will - durch Furcht und Mitleid -, wenn es schon nicht mitspielen darf. Ein bisschen saisonalpittoreske Apokalyptik fürs Gemüt und für Horror-Abende vor dem Fernseher: Läuft gerade kein Splatterfilm, zappen wir eben zur Tagesschau. Mit etwas Abstand betrachtet sind all diese "Krisen» womöglich nicht mehr als ein Kräuseln auf der Oberfläche des Weltgeschichts- 
meeres. Was mich interessiert, sind die langfristigen Veränderungen, und da komme ich zunächst zu einem ähnlichen Befund wie Du auch. Nämlich dazu, dass sich ein garstig breiter Graben zwischen dem demokratischen Anspruch an alle Bürger und Bürgerinnen ...

Können nicht wenigstens wir bei den klassischen Pluralformen bleiben?

Also bei den politisch inkorrekten?

Und damit bei den sprachlich korrekten. Übrigens wirst Du mit der zusätzlichen Endung »-innen « keinesfalls politisch korrekter, im Gegenteil: Indem Du zwar explizit die Frauen nennst, diskriminierst Du alle weiteren denkbaren Geschlechter nur umso mehr. Wohingegen die herkömmliche Pluralform im Deutschen seit Jahrhunderten geschlechtsneutral ist; nur Genderbeauftragte wollen im Genus neuerdings auch den Sexus ausgedrückt sehen, damit sie etwas zu geißeln haben. Die Deutschen gendern, die Chinesen fliegen unterdessen auf die Rückseite des Mondes und erobern die Welt.

\section{Die Verschweizerung Europas als Idee und Erscheinung}

Meinetwegen. Aber verzetteln wir uns bitte nicht auch im Genderisierungsschwindel. Also, es gibt da einen tiefen Graben, der sich zwischen den Bürgern, die sich aktiv am politischen Geschehen beteiligen möchten, und der repräsentativ-demokratischen Realität aufgetan hat, die diese aktive Beteiligung weitgehend unterbindet. Sicher, man darf alle paar Jahre sein Kreuzchen machen, man darf sich an Bürgerinitiativen und Demonstrationen beteiligen, aber was man in Deutschland nur nach Überwindung hoher Hürden darf: politische Sachentscheidungen selber fällen. 